\title{
The Current Situation and Countermeasures of Mandarin Education in Northern Thailand under the "Belt\& Road" Initiative
}

\author{
Zhixiang Xie \\ Communication School \\ Yunnan University of Finance and Economics \\ Kunming, China \\ xzxkm@163.com
}

\begin{abstract}
China has made remarkable achievements on Mandarin promotion during last decades all over the world, especially in Northern Thailand. Nevertheless Mandarin education faces challenges and obstacles in the context of Belt $\&$ Road initiative. Several countermeasures should be adopted to tackle the problems arising in Mandarin education in northern Thailand.
\end{abstract}

Keywords-Belt \& Road initiative; Mandarin education; northern Thailand

\section{INTRODUCTION}

The background of northern Thailand is similar to Yunnan. Yunnan has a long history of migration to Southeast Asia via the ancient Chama Trail. Later, due to geographical relations, economic and political reasons, a large number of Yunnan has entered northern Thailand via Myanmar and continue to enter south-central Thailand from northern Thailand. There are more than a hundred Chinese villages scattered across the mountainous regions of Chiang Mai, Chiang Rai, Chiang Rai and Sihong Song. Decades have passed and there are now more than 300,000 refugee villages. What's most commendable is that they still speak Yunnan dialects in their daily lives. They accept local Thai language education while maintaining their native language learning when they integrated themselves into the Thai society. They spare no efforts to actively carry out Chinese language education. Chinese language education refers to the development of Chinese language and culture education for non-Chinesespeaking overseas Chinese as the teaching object.

In 2013, during the visit to Central Asia and Southeast Asia, Chinese President Xi Jinping put forward the major initiatives of jointly building the "Silk Road Economic Belt" and "21st Century Maritime Silk Road". Thailand is an important fulcrum country for the " 21 st Century Maritime Silk Road". Because of the same language and emotional connection with the implementation of the "One Belt and One Road" policy. China and Thailand have conducted extensive tourism, agriculture, transportation, science and technology and other fields. Cooperation has benefited nationals of both countries. The exchanges in the economic and cultural fields have also promoted the development of the field of education.
Chinese-language education has a richer content and broader needs in Thailand.

In February 2017, the author went to the Chiang Rai Chiang Rai region in northern Thailand and found that the Chinese education in the "Refugee Village" in North Thailand is facing rapid development, many problems and challenges. It has become a important issues that concerned about the development trend of Chinese education in North China in the new era, combining local Chinese education status, formulating relevant countermeasures to promote the development of Chinese language education in Northern Thailand so that it can play an active role in the construction of "One Belt and One Road".

\section{The Present Situation of Chinese EdUCATION IN THE NORTHERN THAILAND}

There are three main types of schools in the Chinese language taught in Thailand: the first is the government run universities, which will directly open the Chinese language teaching in Chinese; the second is the public or private vocational school approved by the Ministry of education. The Chinese courses offered by these schools are generally selected courses; the last category is taught in Thailand. The private Chinese primary schools approved by the Ministry are funded by overseas Chinese or overseas Chinese associations [1]. The Chinese education in the Chinese village of the northern Thailand refers to the Chinese private schools and their educational activities.

At present, the education system of the Chinese language in the northern Thailand is more consummate, the level of running school presents the structure of Pyramid, the education of all levels of high school, junior high school and primary school has already been possessed, the basic education has been fully covered and the structure of the school running level is reasonable. As one of the early settlements of Chinese immigrants, Thailand area is located near the Chinese language area, with a relatively deep Chinese cultural foundation. It is one of the most concentrated Chinese schools in Thailand and one of the earliest areas in Chinese teaching. Therefore, the Chinese language education has a 
good tradition. The overall development of the Chinese language is relatively mature and the level is high. All levels of Chinese teaching are fully available. As of 2009, the number of Chinese Schools opened in Thailand has reached more than 100. More than 30 middle schools, and some also set up high school; There are 16 universities in 17 northern Thailand, 3 of which are private universities, 7 are royal universities, and Chinese courses are offered in 15 universities [2]. In addition to offering Chinese language teaching in national education institutions, there are various Chinese language training institutions and folk Chinese culture and education centers in Thailand. Chinese education in northern Thailand is booming, but due to historical and other factors, Chinese education in northern Thailand still faces various problems.

\section{A. Textbooks Problem}

In the past, Ethnic Chinese schools in ethnic Chinese villages have been using the Textbooks provided by the Taiwan authorities, which are influenced by the writing style, the language standard, the form of Chinese characters, and even some of the ideology that has been formed. In recent years, Chinese schools have begun to use textbooks provided by mainland China. The Textbooks for first grade to grade three of the kindergarten in North China are "children's Chinese", which is written by Thailand Hua Wen Min Hui publishing house. This set of Textbooks is practical, suitable for beginners of Chinese, but the content is rather old. The textbooks selected from primary schools to junior high schools are the series of Chinese textbooks compiled by the Chinese Language Institute of Beijing. The chief editor is Peng Jun, published by Jinan University press. In the middle stage of Chinese language teaching, the Chinese language course is published by the Beijing Language and Culture University press [3].

All Chinese textbooks are donated by the China Overseas Exchange Association. The Yunnan Overseas Exchange Association is responsible for statistical transportation and distribution. In the survey, the Yuying middle school began to use Chinese textbooks donated by Han overseas Chinese in 2007, and began to use the nine year compulsory textbooks published by the people's Publishing House in March 30, 2009 Some schools' textbooks are self-made and self selected, and other schools are supported by traditional Chinese language teaching styles. In our survey, many teachers reflected that the Textbooks were not up to the standard of students, and could not arouse students' enthusiasm for learning and interest in learning. The selection of Textbooks is lack of systematicness. Generally speaking, the quality of Chinese Textbooks in Thailand north schools is not good enough, and the teaching effect is difficult to be unified.

\section{B. Student's Problem}

In the survey, we found that many students in northern Thailand Chinese school have "Chinese language difficult", "learning Chinese language is too little time", "in Thailand, Thai and English are the most important", "the importance of Chinese language is not enough" and other issues. In terms of quantity, there are not many students who lack interest and initiative in learning Chinese. This shows that due to the "embarrassing" environment, students have difficulty in learning Chinese. According to statistics, They study on an average of 9 hours a day and only spent 2.75 hours in Chinese learning [4]. Most Chinese students no longer contact Chinese after graduating from high school. After a few years, Chinese knowledge is gradually forgotten. This is the main factor that inhibits the enthusiasm of students in Chinese learning. Because students lack motivation in their learning process, lack of interest in learning and enthusiasm for autonomous learning, they often feel bored and bored.

\section{Teachers' Problem}

In our survey, we found that the problem of teachers has become the most restrictive factor in the teaching of Chinese in the northern Thailand. The composition of teachers is complex and diverse. The source of Chinese teachers in the Chinese village of the northern Thailand is complex, teachers' educational background is uneven, and the level of teaching is generally low.

The sources of Chinese school teachers are complex. Generally speaking, they can be divided into four categories: $40 \%$ of the teachers belong to the native Chinese descendants of the local Yunnan and the local minority that have been Sinified; $30 \%$ of the teachers are directly from the mainland of China, and $20 \%$ of the teachers are Burmese (mostly Chinese Burmese) in Burma, and $7 \%$ of the teachers are migrant teachers, namely, Burma, mainland China and Taiwan, and Thailand public schools. The Chinese teachers of the school teach in the Chinese primary and secondary schools in the Chinese villages due to teaching and other reasons, and $3 \%$ of the teachers are volunteers from Taiwan (most of them are retired teachers) [5].

We also understand the situation of teachers in $\mathrm{Yu}$ Ying middle school, Changliang village, Chiang Mai: Yuying middle school has twenty-four teachers and one principals. Among the Twenty-four teachers, ten of them are local teachers, five of them are local Yunnan Chinese descendants, five of them are from Burma Chinese school, seven of them are Chinese expatriate teachers, and the six of them are from Zhaotong college students. President Mu Shaowei is a Chinese descendant. These different components of Chinese teachers bring different teaching methods and ideas to Chinese teaching in Thailand, and produce various teaching styles at the same time.

The teaching level of Chinese teachers in Thailand is uneven. Some Chinese teachers who have been taught in Thailand are undergraduate and graduate students of foreign Chinese specialties, with rich professional knowledge, strong teaching skills and higher teaching level. Some teachers are from other liberal arts majors, and the teaching skills of Chinese are weak and even some specialties, such as English majors and management majors. Also in Thailand, Chinese teaching work, because of the lack of systematic professional study, their basic knowledge of Chinese and teaching skills are very short, the teaching level is not high, directly affect the quality of Chinese teaching.

Chinese teachers are unstable and Chinese teachers are poorly treated. Teachers and volunteers from the national Han 
Office of the state are the main force of Chinese teachers in Thailand, but the mobility of the volunteers is very large, most of them will return home for one or two years in Thailand. And the Chinese teachers who teach in Thailand through other channels are generally low. Many people turn to other professions with higher wages. Since the school funds were originally made up by the school board, even the basic teaching conditions could not be met, not to mention the teachers' wages, the local Chinese language teachers were very difficult to live. They were mostly engaged in other agricultural labor or commercial activities in the daytime, and returned to school at night. The treatment is too low, and teachers' enthusiasm cannot be mentioned. Let alone every school has a solid teaching team. As a result, the Chinese language teachers in Thailand are very unstable. Basically, more than half of the Chinese teachers will be replaced in one to two years.

\section{The problem of teaching mode}

Due to various reasons, such as teachers, Textbooks and so on, the teaching mode is obsolete and traditional. Teachers have become accustomed to filling in the teaching model: For example, the teaching of literacy is simplified as "book space, number of strokes, and confess". The teaching of words is simplified to read the notes of the dictionary or teacher's manual to the students, and after the dictation, the students should copy the notes.

The teaching of the reading course is also a mechanical practice. The teacher puts the emphasis on the teaching of the word. One lesson will explain the word for about 30 minutes in a lesson, and then talk over the text again. There is a lack of interaction between teachers and students. Students are also lazy and not motivated to cooperate with teachers. The classroom teaching does not take into account the differences between the starting point of the students' learning and the differences of the existing knowledge and the actual ability of the students, and the teachers cannot carry out the reform and content of the classroom teaching according to the actual situation of the current Chinese language teaching.

\section{THE DEVELOPMENT OF CHINESE EDUCATION IN NORTHERN THAILAND IN THE “ONE BELT AND ONE ROAD”BACKGROUND}

In October 2013, China Malaysia relations were upgraded to a comprehensive strategic partnership. In the construction of "The Belt and Road" new opportunities for development, the practical value of Chinese has become increasingly prominent, the Chinese learning upsurge again swept Thailand, Thailand language education also ushered in the best period in history.

\section{A. Chinese Education is More Open and Inclusive.}

The enthusiasm for learning Chinese in Thailand has increased year by year. It is reported that as of 2016, more than 3000 schools in Thailand have set up Chinese language courses, from more than 80 thousand in 2003 to more than 1 million of Chinese learners at present, and a larger number of schools in all kinds of language training schools. At the same time, In 2013 the number of Thailand students who came to
China was more than the students from Japan, and has been the third of the total number of foreign students in China after South Korea and the United States, and most of them also choose to study Chinese language and literature, Chinese International Education and other majors [6].

The concept of modern Chinese education is established. The local Chinese believe that Chinese education is the inheritance of the Chinese culture. They generally believe that only through Chinese education and through the Chinese culture can make the Chinese children feel that they are Chinese. Chinese education can be said to be a powerful means to strengthen the unity of overseas Chinese. In addition, under the premise of "multiple identification", the northern Thailand Chinese school is no longer a single cultural inheritance function, and the economic benefit of "practical value" has become a significant inducement. In particular, the development of the Greater Mekong subregion, the deepening of the cooperation between China and ASEAN, the formal recognition of the Chinese language education by the government of Thailand, the political and cultural pressures of Chinese education, and the opportunity for the new development of Chinese language schools. Representing the highest level of Chinese language in Thailand, the function of Chinese education in Thailand has shifted from cultural needs to practical needs [7].

\section{B. Thai Government and Chinese Community Support Chinese Education}

The government of Thailand has long adopted a relatively tolerant, mild and encouraging policy on Chinese language education and Chinese teaching in the region, setting up a national model of teaching and setting up a pioneer institution in the area, which has played an exemplary role in the form of school running in other places [8]. Overseas Chinese invested most enthusiasm in developing Chinese education. The association of Chinese folk schools in northern Thailand was established in 2003. It was jointly established by fourteen schools in the northern Thailand. It is an overseas Chinese organization dedicated to coacing the power of schools in the north ern Thailand and promoting the coordinated development of the Chinese language education in the northern Thailand. With the active promotion of the fellowship of the Chinese folk school in the northern Thailand, through the selection and provision of teaching materials, training and training of teachers, and the organization of Chinese students' activities, The Chinese language education and teaching in many member schools have been on the way of scientific management, and have achieved some success and become the pioneers of Chinese education in Thailand.

At the same time, by giving full play to the example of the demonstration school, the association of Thai and Chinese folk schools also promoted the development of the local Chinese education, helped the other Chinese schools to raise the school level and further promoted the development of the Chinese language education in the north of Thailand, and was widely praised by the University of Thailand and the vast majority of teachers and students [9].

In May 6, 2017, the Preparatory Committee for Chinese education in Tai Bei and the Preparatory Committee for the 
Thai North Chinese education charity foundation was held in Chiang Mai, Thailand. About 100 people represented 12 overseas Chinese associations, Chinese schools and Confucius institutes in northern Thailand. Ren Yisheng, Consul General of China in Chiang Mai, pointed out in his speech that education is the foundation of all ages. With the great importance and support of the Chinese and overseas Chinese, the Chinese language education in the northern Thailand has made great progress in recent years, and it also faces many problems and challenges. The relevant government departments of ancestral countries and the general consulate in Chiang Mai attach great importance to the education of the Chinese language in the northern Thailand, and provide support and guarantee in the fields of funds, equipment, teaching materials and teachers [10].

\section{Chinese Education has a Good Prospects for Development}

The economy and culture are inseparable, the concept of "The Belt and Road" embodies the culture first, educational and cultural cooperation not only for cooperation in other areas and lay a solid foundation of public opinion, more conducive to explore along the profound human resources. The strength of national strength, the local Chinese are more proud, and encourage children of the fourth and fifth generation to learn Chinese well. The government of Thailand has also constantly adjusted its attitude towards Chinese education and strengthened cooperation with China.

In October 2013, Premier Li Keqiang visited Thailand and published a speech entitled "let the flowers of China and Thailand produce new fruits", which is the first time Chinese leaders made a speech in the Thailand Congress. At the same time, the two countries issued a vision plan for the development of Sino Thai relations. In December 2014, Prime Minister Ba Yu visited China.

In 2015, when China and Thailand established diplomatic relations 40th anniversary, high-level exchanges and visits between the two countries were carried out. These measures will undoubtedly help Thailand's Chinese fever. Nowadays, learning Mandarin in Thailand means a broader employment prospect. More and more people take the initiative to take part in the HSK. Thailand is located in the center of the Chinese cultural circle. It has both the immigrants from the mainland of China, the refugees and the border people migrated from Burma, the frequent language contact and cultural contact, and the local integration of language. The two-way channel of language input and output is more smooth.

Because of the local demand for local talents with Chinese advantages, all kinds of talents who have received Chinese education can be easily transformed into important local human resources, so the education market has a bright future [11]. "People who know Chinese have more job opportunities and higher wages." Zhuang Xiuqin, vice president of the Thailand Chinese teachers' Union and President of Bangkok overseas Chinese School in Bangkok, said that learning and mastering Chinese in Thailand is becoming more and more important. "People who can speak Thai, Chinese and English, all kinds of companies are fighting for it; the people who speak Chinese and Thai, the company must; the people who only speak the Thai and English will consider the use of it" [12].

\section{THE SOLUTION OF CHINESE EDUCATION IN THE NORTHERN THAILAND UNDER THE BACKGROUND OF “ONE BELT AND ONE ROAD”}

\section{A. To Strength the Sustainability of Institutional Management}

The Chinese office of overseas Chinese and the office of Han Dynasty increase direct investment in education funds in the Northern Thailand, which can solve the difficulties in the lack of financial resources of the Thai school and the inability of the quality of teaching. At the same time, we carry out the supervisory system between capital input and annual review. And the school and the management institution review expatriate teachers' achievement and students' learning Chinese level together. Forming a regular system to implement strictly can effectively improve the enthusiasm of expatriate teachers and students' Chinese level.

In addition, most Chinese principals were replaced frequently in the Northern Thailand now. Resulting lack of management continuity is very bad to the stable development of Chinese Teaching. I advise to employ a local Chinese President who is able to work for a long time. It's easy to implement stable, long-term and effective guidance and management. Meanwhile, the association should improve the construction of the management organization of the Chinese Department, and further develop excellent manager. It's to formulate the development of Chinese and to insist on the continuity of management.

\section{B. To Strength the Supervision and Evaluation of Chinese Teaching}

Now, there is still no standard Chinese Syllabus for basic education in Thailand. So the Thai government and the Chinese side need to work together to set up a standard Chinese teaching syllabus as soon as possible, and to improve and implement. This can effective assess the teaching work of the Chinese Teaching, which can achieve the purpose of supervising Chinese teachers and the quality of improving Chinese Teaching. On the teaching material, Han office of overseas Chinese office provides a systematic textbook for Chinese, mathematic, history, geography and nature. On the span, it's can from kindergarten to primary school or even "nine years". On the content, it chooses a comprehensive, concise, lively and interesting Chinese teaching material. In addition, we can make the most use of the local Thai and Chinese teacher and educational institutions to write applicable local teaching materials and to provide a revised syllabus model.

\section{To Strength the Construction of the Teachers' Team}

In the Northern Thailand, the government should build a relatively stable and excellent localized teacher group as soon as possible. Relevant departments of the Chinese government cooperate with relevant departments of Chiang Rai government in Thailand to train local teachers schematically, objectively and systematically. The main training courses are Chinese, language, language teaching, psychology, education, 
Chinese culture and Chinese literature, and it should be a long team training. And it should improve the salary and welfare of the teachers. Besides, the teachers of the overseas Chinese are young and strong. They play an important leading role in the academic fields indispensably. Therefore, extending the duration retention of the overseas Chinese teachers and approving to carry family members can achieve to keep these teachers' staying. It also can ensure the steady development of overseas Chinese Teaching. The teachers of Chinese and Thai work and manage together. Each office set up a Chinese leader. It not only promotes mutual understanding and mutual support between Chinese and Thai teachers, but also expands the influence of Chinese on Thai teachers. Meanwhile, Chinese teachers can also integrate the school more quickly, and can improve self-discipline to help teaching through learning some simple Thai language.

\section{To Change the Traditional Teaching Mode and to Develop Characteristic Teaching Activities}

As a Chinese teacher, we should hard to study pedagogy and educational psychology to mobilize the students' enthusiasm for learning. We should change the traditional teaching model of "learning by the book and instilling knowledge" on time, and make sure the classing model of "training" to focus on "listening speaking reading". On the content of teaching, our teachers also should increase topics of interest to children and young people such as Internet, Hong Kong and Taiwan superstars, pop songs and so on. Combining these contents with teaching materials can enhance the interest of Chinese learning. Our school also should strength the hardware construction, and provide more multi-media classroom to create a good Chinese learning environment for students, and to facilitate the interaction between teachers and students, and to enhance the interest of Chinese classroom. The school should organize more activities about Chinese traditional culture, and carry out experiential teaching. Therefore, students can understand Chinese culture in activities and can improve Chinese communication level.

\section{CONCLUSION}

Now, the functional orientation of Chinese education in Thailand has gradually shifted from mother tongue education to the guidance and service of Chinese language in Thailand. It enters a new stage. Therefore, the Chinese education in the northern Thailand under the background of "the Belt and the Road" should respect the local actual situation. Coordination with the global development, we should strength cooperation and exchange on the platform of cross-cultural communication to achieve all-around services in the international perspective of language and culture, and to benefit more people in china and Thailand.

\section{ACKNOWLEDGMENT}

We would like to express our gratitude to all those who helped me during the writing of this thesis. This research paper was partially supported by Communication School, Yunnan University of Finance and Economics. Also as phased achievement, it is sponsored by National Social Science Research Project, Comparative Research on Investigation into Yunnan Dialect of Thai Mandarin (16BYY048 ). We thank our colleagues from Communication School who provided insight and expertise that greatly assisted the research.

We would also like to show our gratitude to the moderators for sharing their pearls of wisdom with us during the course of this research. And we also immensely grateful to reviewers for their comments on an earlier version of the manuscript. In addition, we would also thank peer reviewer for comments that greatly improved the manuscript.

Last, but not least, we recognize that this research would not have been possible without the financial assistance of the University of Finance and Economics, and other institutions, and express my gratitude to those agencies.

\section{REFERENCES}

[1] Ye Yan.The current situation, Difficulty and Outlet of Chinese Education in Thailand[J].Journal of World Eduction, 2012(Z1)

[2] LI Zhiling. An Introduction to Chinese Teaching in Northern Thailand with Evaluation in the Supra-Chinese Context[J].Journal of Research on Education for Ethnic Minorities,2016(1)

[3] Jin Ya. The Development of private Chinese Schools of Northern Thailand[D].Tianjin Normal University,2016.

[4] Huang Qiqing \& Wu Yanjiang. A Survey of the Chinese Situation and Education in the Chinese Village of Northern Thailand[J]. Journal of Jiangxi Science \& Technology Normal University, 2011 (1)

[5] Zhao Min. Chinese Language Education and Language Use in Huaren Village, Chiang Mai, Northern Thailand[J]. Confucius Research, 2011.

[6] Chen Boqian. The Causes and Reflections on the "Chinese Band" and "Taiwanese Way"[J]. Overseas Chinese Education,2017(2).

[7] Yang Wenan An Analysis of Yunnan Chinese Community in Northern Thailand and Chinese Education[J]. The Ideological Front(Yunnan University's Journal of Social Sciences),2011(A2).

[8] LI Zhiling. An Introduction to Chinese Teaching in Northern Thailand with Evaluation in the Supra-Chinese Context[J].Journal of Research on Education for Ethnic Minorities,2016(1).

[9] Jin Ya. The Development of private Chinese Schools of Northern Thailand[D].Tianjin Normal University,2016.

[10] Thailand: Thailand North China Education Charity Foundation Organizing Committee established[J]. Overseas Chinese Education,2017(6).

[11] LI Zhiling. An Introduction to Chinese Teaching in Northern Thailand with Evaluation in the Supra-Chinese Context[J].Journal of Research on Education for Ethnic Minorities,2016(1).

[12] Thai-Chinese Educators: In Thailand, Understanding Chinese Becomes a Magic Tool forJob Hunting. http://edu.sina.com.cn/a/2018-04-19/docifzihnep8257493.shtml 